\title{
On the analysis of building a public information platform based on e-Commerce for coal logistics
}

\author{
Zeguo Qiu \\ School of computer and information engineering, Harbin University of Commerce, Harbin, Heilongizang (China) \\ qiureguo@sina.com
}

Received: March 2013

Accepted: August2013

\section{A bstract:}

Purpose Putting forward the concept and features of the public information platform for coal logistics based on electronic commerce, as well as the requirements of upper and lower intersections of the coal supply chain. Meanwhile, this paper will also probe into the current condition of statistics management in coal logistics, and then discuss how to build a public information platform based on electronic commerce for coal logistics.

Design/mathoddogy/approadr According to the further exploring the concepts and relevant characteristics and the development of coal logistics and supply chain management in China of the current period.

Findings/practical implications: An advanced public information platform for coal logistics utilizes to best advantage modern information technologies and managerial concepts in the operation of coal logistics, such as e-commerce, e-information, supply chain management, etc. This not only stimulates efficient integration of business flow, information flow, logistics and capital flow of the coal industry, brings about in-depth integration of the logistics resources of the coal industry, but also greatly improves the efficiency of the operation of coal logistics, reduces the cost of coal logistics, and enhances the overall competitiveness of upstream and downstream companies along the coal supply chain.. 
Researd limitations/implications: Although the coal logistics public information platform has been applied in some enterprises in China, not yet in a broader range of applications, which need the joint efforts of all parties.

Originality/value Fitted to the e-commerce era, the Public Information Platform for Coal Logistics envisioned in this article is highly feasible and worthy of reference to relevant institutions.

Keywards: coal logistics, supply chain management, electronic commerce, public information platform

\section{Introduction}

In an energy structure analysis in China, coal, famed as 'industrial food', accounts for nearly $70 \%$ of the total share, and will remain irreplaceable in the long run. It remains a big challenge, especially for China, to find alternative sources of energy. Concerning the irreplaceability of coal and the uneven distribution of coal in China, the development of coal logistics becomes quite essential.

Nevertheless, currently speaking, the industry of Chinese coal logistics remains at an initial phase, resulting in high costs of coal logistics. Statistics show that the transportation cost of coal in Shanxi province accounts for $28 \%$ of the final sales price, much higher than $18 \%$ (the account of Chinese logistics costs in the GDP). Take Datong for example, if coal of $5000 \mathrm{Kcal} / \mathrm{Kg}$ is transported from Datong to Qingdao port by train, the factory price is $560 \mathrm{RMB} /$ ton, and the bargaining price on the vehicles is $620 \mathrm{RMB} / \mathrm{ton}$, while the final price is $750 \mathrm{RMB} /$ ton. From this example, we can see that the transportation price has accounted for more than $20 \%$ of sales price. Statistics above are sufficient to demonstrate that the costs of logistics have become a constraint limiting coal production and sales in our country.

Among all the factors impeding the development of coal logistics, the uneven distribution of coal has also become a major one. Up until now, coal deposits in Inner Mongolia, Shanxi and Shaanxi occupy nearly $70 \%$ of the total deposits nationwide, while the main consumer regions are Yangtze River Delta, Zhujiang Delta and Bohai Rim Region, respectively accounting for $25 \%, 12 \%$ and $35 \%$ of the total consumption. In addition, Chinese coal consumption varies by season, which means that in summer and winter when the electricity is in high demand, the requirement for coal also grows, contributing to greater difficulties of coal logistics. With regard to these greatly asymmetrical relationships between coal distributions and consumption regions, and peak load and seasonal features, it's certain that many obstacles must be overcome in the road to the development of coal logistics in China. 
About coal logistics, domestic and foreign scholars' research focused on the following aspects. Yunliang and Shaopeng (2008); Xifeng and Jing (2004) think the system of coal logistics is a complex system, composed of Supply, production ,marketing, recycling. They analysis the structure and characteristics of coal logistical system deeply, and construct the framework of the logistical network of coal, the comprehensive evaluation system of coal logistics and the information platform of coal logistic system. Berman, Drezner and Wesolowsky (2002) point out the important of facilities in the decision of the logistic center's location and the application of information in it. Gattuso and Cassone (2012), proposing a stochastic, dynamic discreteevent micro-simulation model, analyze the operation of logistic platform to determine its performance. Aldin and Stahre (2003) analyze the logistics conducting electronic commerce, marketing channels and flexibility. By researching cases, they give some indications of the potential of electronic commerce and logistics platforms. The research of Lai, Wong and Cheng (2008), shows that electronic integration is not sufficient for delivering superior logistics services.

\section{The concept, current condition and problems of coal logistics}

When it comes to the concept of coal logistics, there are various definitions in different domestic research institutions. However, from the perspective of the public, and in the era of supply chain management, coal logistics refer to a dynamic circulating process (Zaklan, Cullmann, Neumann \& von Hirschhausen, 2012) of a series of goods and materials (which include coal, raw materials, mechanical equipment and so on) in the coal supply chain management (which includes all upper and lower intersections of the supply chain ranging from material purchase and supply, coal production and sales to reverse logistics) so as to ensure a better circulation of coal. As the Figure 1 illustrates:

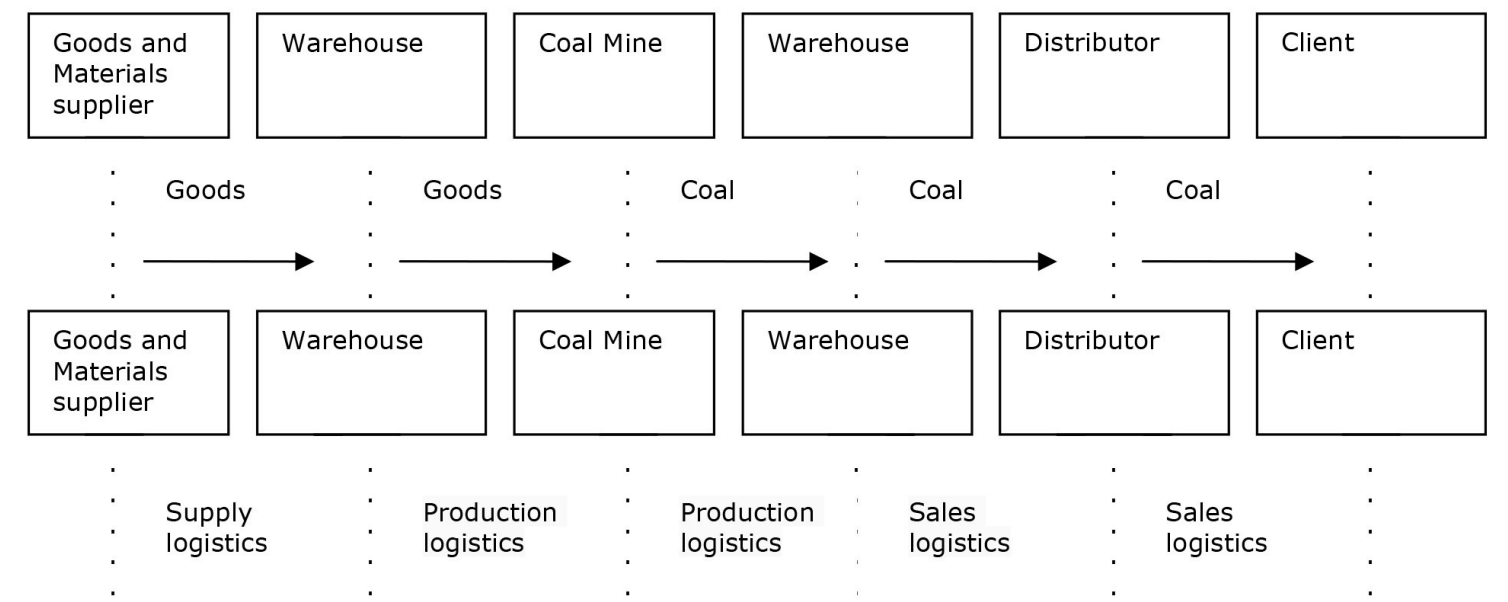

Figure 1. The dynamic circulating chart of goods and materials in coal logistics

In respect of coal supply chain management, the logistics system of the current domestic coal industry is divided into three main phases: goods and materials supply logistics, production logistics and sales logistics. The press has frequently reported on issues like electricity and coal 
transportation and the transportation of coal from Shanxi province to other places, which illustrates the difficulty of coal transportation and exerts a negative effect on the coal industry development. Therefore, the sales logistics have gained great attention and become a key research topic for experts, scholars, enterprises and public institutions.

The importance of sales logistics of coal can be fully demonstrated from the following several groups of statistics. According to the requirements of the National Development and Reform Commission, the goal of regulating trans-provincial coal transportation in 2011 were 932 million tons, which only grew by $2.8 \%$ - the lowest growth rate for several years. As a major coal-consuming sector, the electricity industry consumed 769 million tons of coal in 2010. However, as the main transportation means (for example, in 2011, the export amount of coal in Shanxi province were 581 million tons, among which 456 tons were transported by railway, accounting for $78 \%$ of the total), the railway is still confronted with many problems and difficulties. Experts have estimated that the structural obstacle of coal supply will remain until 2015.

Various difficulties of coal logistics (which mainly refers to the link of sales logistics, similarly hereinafter) have greatly influenced the production and supply of Chinese coal industry. However, with regard to the characteristics of coal production and supply, and the fact that third party logistics are unable to meet the requirements of upstream enterprises, coal logistics are still carried out by coal production enterprises (coal mines), trade companies and logistics enterprises which have been spilt from former coal production enterprises. Although these logistics enterprises partake of logistics socialization, they are still focused on guaranteeing interior coal logistics.

From what has been discussed above, the current development condition of Chinese coal logistics are embodied with the following features. To begin with, due to the long distance of coal logistics and a great number of involving segments, coal logistics enterprises tend to be scattered and subject to disorderly competition. Secondly, the high pressure of railway transportation has directly affected the efficiency of coal supply, and activities like "jacking up wagon price" have intensified the pressure of train transportation as well as led to unreasonable coal price growth. Third, coal trade enterprises are too many to be counted, accompanied by improper operating behaviors, numerous middle segments and high trade costs. The forth feature is a lack of advanced ideas of logistics management. Logistics management methods, technical means and logistics equipment are outdated, and logistics costs are too high. In the fifth place, services and functions of logistics enterprises are monotonous, and there is a lack of integrated supply chain management concept. Most logistics enterprises are primarily engaged in low levels of operations like preparing goods for delivery, transportation, storing goods, loading and unloading goods and ensuring in advance the transportation capability and so forth. Few enterprises are capable enough to offer services like circulating and processing goods, which include separating and choosing goods, removing 
gangue, blending coal and final forming, logistics surveillance and the management of ordering and storing goods.

How to change the current condition of Chinese coal logistics industry? In light of the present mainstream opinions (Zhao, Chen, Leung \& Lai, 2010), the solution lies in improving the current transportation situation, introducing modernized concepts of logistics management, strengthening supply chain management ideas of coal enterprises, accelerating institutional reform and industrial integration within the field of coal logistics, promoting the development of third party logistics, and spreading the application of information technology for coal logistics. This paper will, through demonstrating the importance of building an information platform for the development of coal logistics, offer some suggestions to related enterprises for reference.

\section{The analysis of building an information platform}

\subsection{The concept of an information platform}

The public information platform which has been mentioned in the paper refers in particular to the one in the circumstance of electronic commerce (e-commerce).

To build a public information platform for coal logistics, the first step is to have a clear idea about coal logistics information. As far as the author is concerned, coal logistics information is a variety of statistics which can reflect the operational condition of coal logistics and promote its highly efficient operation. However, since coal logistics are involved in a great number of links and an extensive range of aspects, and the management is complex, information about coal logistics is in eager demand.

Nevertheless, concerning relevant enterprises' weak awareness of coal logistics information management, information collection, conveyance, exchange, and information sharing and processing in the current phase are always lagging behind. Consequently, the efficiency of coal logistics is gravely affected, logistics costs are fundamentally growing, and energy resources are heavily squandered. Moreover, for a single coal enterprise, especially the one of small or medium size, it is not realistic to build a coal logistics information system on its own, nor is it to establish a cooperative one from the perspective of the whole supply chain. Therefore, the most favorable choice is to build an open public information platform based on e-commerce and can meet the needs of enterprises within it. Such a platform can, in turn, better perform the tasks of information collection, conveyance, exchange, and information sharing and processing, and finally serve as the basis for enterprises' decision-making.

\subsection{Functions of information platform}

The Public Information Platform for Coal Logistics referred to in this article is a MIS (management information system) of high level of information density based upon Web 
Services. Its functions include the gathering, transmitting, storing, processing, sharing and providing of public information. Through this, it can offer information support and transaction services to both upstream and downstream companies along the coal supply chain in terms of logistics management. Also, it is compatible for the one-stop service platform of the government department.

This information platform has the following features:

- Being a platform designed for the operation and coordination of the coal logistics business, it can provide one-stop service interface to upstream and downstream companies along the coal supply chain and facilitate the communication, business operation and coordination among the upstream and downstream companies along the supply chain through a wide range of coal logistics information, such as instructions, plans, documents, data, reports, and market intelligence.

- It contains various technologies, such as mobile communication service, electronic data interchange, GPS tracking of cargo (vehicles and equipment), short message platform, intelligent card (inventories, collection of trade charges) real-time checking, etc, which enables the coal logistics operation to go electronic.

- Due to its capacity for information processing, it is not simply a platform of information exchange. Instead, it enables upstream and downstream companies along the coal supply chain to get a better understanding of the pattern of development and change in coal logistics by way of deep processing of coal logistics information. In addition, it can have a major impact on decision-makers in terms of goods and materials purchasing, storage management, vehicle (railway wagon) dispatching, transport procedure designing, and cost-benefit analyses.

- It also includes the function of electronic transaction service and provides a virtual electronic transaction platform for both suppliers and buyers of coal logistics. This eservice combines business flow, information flow, goods ordering and delivery, storage, transport, clearance of goods, financial settlement, and so on.

- It provides the service of membership registration of differing levels (permission) for upstream and downstream companies along the coal supply chain based on the verification of their qualifications and background identities. Members of different levels will enjoy different made-to-measure services, which include the provision of tailored information index and content, basic information management of members, data storage and analysis, etc.

- It has the function of "intelligent logistics," which means that the platform is able to help make the optimal coal logistics solutions by processing information concerning coal 
supply, consumer demand and transport resources which is provided by upstream and downstream companies along the coal supply chain as well as relevant public information. In this way, it will enhance transport efficiency and reduce transport costs.

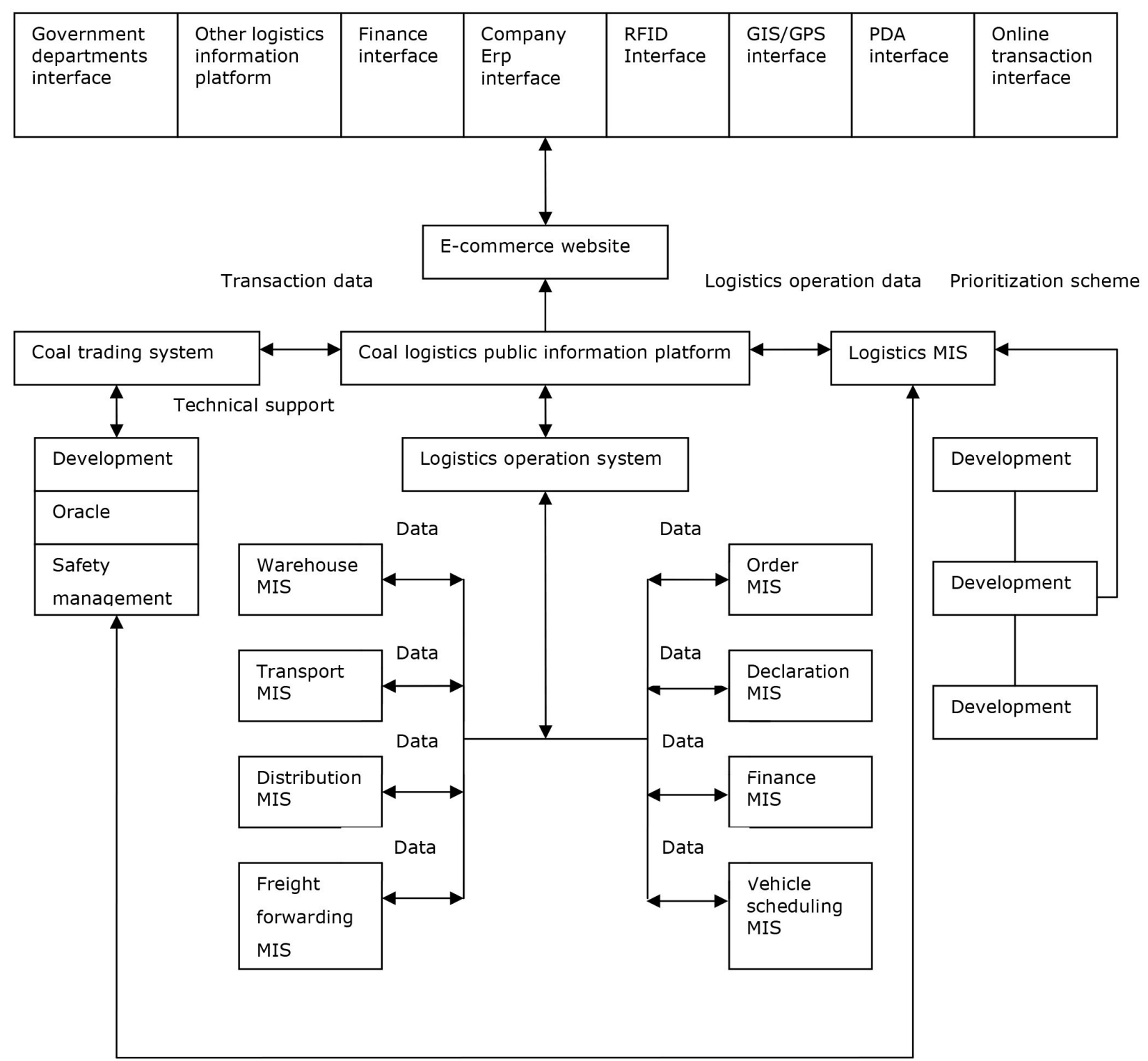

Figure 2. Flow chart of the Public Information Platform for Coal Logistics

\subsection{Construction of information platform}

The Public Information Platform for Coal Logistics referred to in this article is a open Web platform which stimulates better integration of coal logistics resources and improves the logistics information management of upstream and downstream companies along the coal supply chain. At the same time, it will have great impact on increasing coal logistics efficiency, realizing the social benefits and maximizing the economic returns of coal logistics. In the process of the construction of this information platform, there are several principles which the author holds firm to: foresightedness, economic viability, security, openness, compatibility, and expandability. 
The platform envisioned in this article consists of two closely related sub-platforms-coal supply and coal sales. They are made of updated coal supply data, coal sales data and coal logistics data. The division of the platform and data is conducive to the centralized management and optimization of the entire coal logistics supply chain.

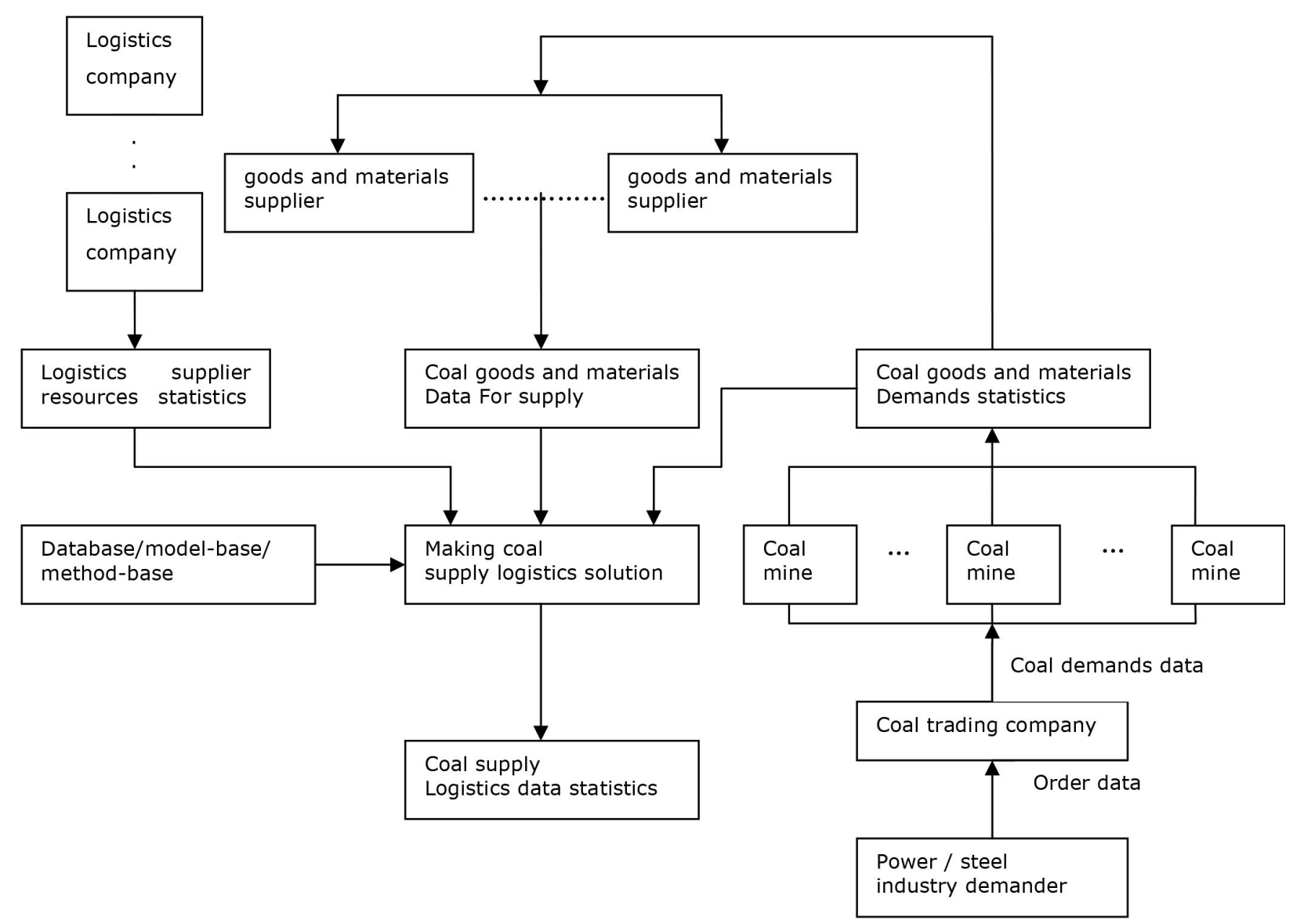

Figure 3. flow diagram of logistics information platform for coal supply

As is shown in the diagram above, coal demanders-the electricity/steal/etc. companies in the downstream reach of the coal logistics supply chain-send coal order data to coal trading companies who send out detailed data of coal sales or order to their partner or affiliated coalproduction companies (coal mines). Upon receiving the data, the coal-production companies can make production plans according to their own abilities and work out the total demand of coal goods and materials respectively. These data will be simultaneously sent to several coal goods and materials suppliers, who summarize their suppliable coal goods and materials data. At the same time, each logistics supplier will bring together the logistics supply information onto the information platform according to their own abilities. Then, the information platform will make logistics solutions to coal supply based on the collected statistics of logistics suppliers' resource, suppliable coal goods and materials of the coal goods and materials suppliers, coal goods and materials demand worked out by the coal-production companies (coal mines). During the solution-making process, database/model-base/method-base will be used to bring out the statistics information of coal supply logistics. Note: The statistics information can be shared. 
The flow design of the logistics part of coal sales resembles that of coal supply (as is shown in Figure 4). Similarly, the making of logistics solutions to coal sales necessitates the statistics of coal sales, suppliable coal and suppliable goods and materials of the logistics suppliers, as well as the summary of logistics statistics of coal sales.

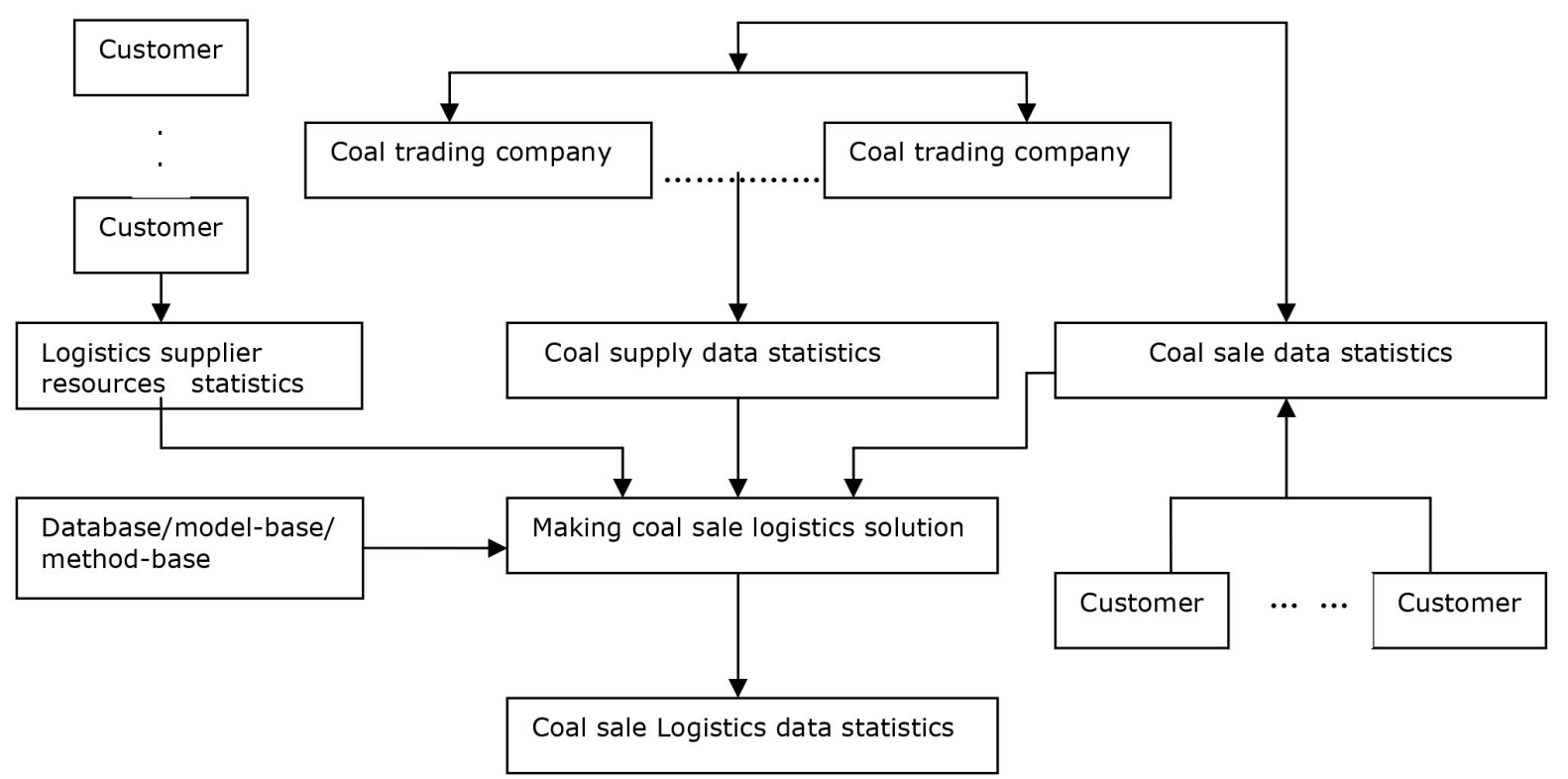

Figure 4. flow diagram of logistics information platform for coal sales

The above logistics information platform for coal sales and coal supply make up the Public Information Platform for Coal Logistics. Due to the relative independence of coal goods and materials supply and coal sales in the coal supply chain, logistics information platform for coal sales and that for coal supply can be equated with the Public Information Platform for Coal Logistics. However, in the long run, the author believes that a completed, optimized and efficient public information platform for coal logistics should be composed of both of the platforms.

\section{Conclusion}

It is an indisputable fact that the development of the coal industry is heavily dependent upon the level of coal logistics. In the development of coal logistics, the construction of the public information platform for coal logistics plays an important role, because an advanced public information platform for coal logistics utilizes to best advantage modern information technologies and managerial concepts in the operation of coal logistics, such as e-commerce, e-information, supply chain management, etc. This not only stimulates efficient integration of business flow, information flow, logistics and capital flow of the coal industry, brings about indepth integration of the goods and materials resources of the coal industry, but also greatly improves the efficiency of the operation of coal logistics, reduces the cost of coal logistics, and enhances the overall competitiveness of upstream and downstream companies along the coal supply chain. Fitted to the e-commerce era, the Public Information Platform for Coal Logistics envisioned in this article is highly feasible and worthy of reference to relevant institutions. 


\section{References}

Aldin, N., \& Stahre, F. (2003). Electronic commerce, marketing channels and logistics platforms-a wholesaler perspective. European Journal of Operational Research, 144(2), 270-279. http://dx.doi.org/10.1016/S0377-2217(02)00393-4

Berman, O., Drezner, Z., \& Wesolowsky, G.O. (2002). Satisfying partial demand in facilities location. HE Transactions, 34(11), 971-978.

Gattuso, D., \& Cassone, G.C. (2012). Micro-simulation Model Supporting the Management of an Interregional Logistic Platform. Procedia - Social and Behavioral Sciences, 54(4), 557-566. http://dx.doi.org/10.1016/j.sbspro.2012.09.773

Lai, K-H., \& Wong, C.W.Y., \& Cheng, T.C.E. (2008). A coordination-theoretic investigation of the impact of electronic integration on logistics performance. Information \& Management, 45(1), 10-20. http://dx.doi.org/10.1016/j.im.2007.05.007

Xifeng, T., \& Jing, Y.(2004). Research on Coal Logistics System Structure. Logistics Technology, 10, 16-18.

Yunliang, W., \& Shaopeng, H. (2008). China's coal logistics network system: optimization and policy side suggestions. China Coal, 34(10), 27-33.

Zaklan, A., Cullmann, A., Neumann, A., \& von Hirschhausen, C. (2012). The globalization of steam coal markets and the role of logistics: An empirical analysis. Energy Economics, 34(1), 105-116. http://dx.doi.org/10.1016/j.eneco.2011.03.001

Zhao, Q.H., Chen, S., Leung, S.C.H., \& Lai, K.K. (2010). Integration of inventory and transportation decisions in a logistics system. Transportation Research Part E: Logistics and Transportation Review, 46(6). http://dx.doi.org/10.1016/j.tre.2010.03.001

Journal of Industrial Engineering and Management, 2013 (www.jiem.org)

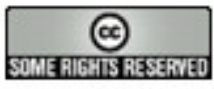

Article's contents are provided on a Attribution-Non Commercial 3.0 Creative commons license. Readers are allowed to copy, distribute and communicate article's contents, provided the author's and Journal of Industrial Engineering and Management's names are included. It must not be used for commercial purposes. To see the complete license contents, please visit http://creativecommons.org/licenses/by-nc/3.0/. 